\title{
Exploring Competition and Labour Productivity in the South African Manufacturing Industry
}

\author{
Stephen O. Adeyemi
}

\begin{abstract}
This research investigates the impact of product market competition on labour productivity in South Africa's manufacturing sector. The analysis is done across the different sub sectors of manufacturing to discover the empirical relationship between these two concepts in the South African context. A review of literature shows that there is a general belief that competition is good for efficiency. Amongst the theories that support this include those of $\mathrm{X}$-inefficiency and industry rationalization. However, there is little empirical evidence supporting the competition-performance connection with the empirical results being inconsistent. A dataset from the World Bank's Enterprise surveys is utilized to yield results for competition, firm size, and labour productivity at the firm level. These are used to conduct empirical statistical analyses to explore and detail the relationship of competition on labour productivity across the manufacturing industry in South Africa. The effect of firm size is also controlled for in the relationship. The results for competition on labour productivity are mixed, whilst that of size on labour productivity are positive.
\end{abstract}

Index Terms - Competition, Firm Size, Labour Productivity, Manufacturing Industry.

\section{INTRODUCTION}

The manufacturing sector in South Africa is the second largest contributor to the Gross Domestic Product (GDP) after the finance, real estate and business services sector. It contributed some $15.4 \%$ to GDP in 2013 [1].

Competition in industry has been measured in a number of different ways which include the use of industrial (business) concentration levels of the Gini index [2] and by the number of competitors for the principal product/service in the main product market [3] amongst others. This research work, similarly, measures competition (product market competition) as the latter.

Productivity is also measured in various ways. The common methods utilize total factor productivity (TFP) or multi-factor productivity (MFP), or just one of the factors [4] which is popular, that is, labour productivity [5]. This research measures labour productivity by using the total sales figures (as the output) per the number of employee months (as the input).

There are quite a number of different diverse theories linking competition and performance (productivity). Most of them

Manuscript received November 6, 2017.

The data for this work was provided by the World Bank's Enterprise surveys.

S. O. Adeyemi is an academic with the Department of Industrial Engineering and Operations Management, Vaal University of Technology, Vanderbijlpark, South Africa (e-mail: stephena@vut.ac.za). belief that competition results in a positive impact on performance. For example, the X-inefficiency explains lowered performance when there is low competition through the under supply of managerial effort [6]. Industry rationalization causes a shift of resources from inefficient to efficient enterprises within and between sectors, thus improving overall efficiency [7]. Other theories include the Schumpeterian, or the agency approach. These support the idea that improved competition can increase effort resulting in productivity growth [8].

Empirical studies of the competition-performance nexus (for example [9]) have mixed results, confirming the issue of the theoretical literature as not so certain [8].

The rest of this paper would look at the data and main variables in section II, followed by the statistical estimation in section III, and finally the conclusion.

\section{DATA AND MAIN VARIABLES}

The data used was collected by the World Bank in 2006 (Enterprise survey). The data is for a cross-section of the manufacturing industry in South Africa (648 firms). The industry classification is according to the International Standard Industrial Classification of all Economic Activities (ISIC Rev 3.1) [10].

\section{A. Dependent Variable}

This research uses labour productivity as a measure of productivity. The dependent variable is actually the (log of) labour productivity. That is, the (log of) total sales (in Rands) of an enterprise in 2006 divided by the number of employee-months needed to generate the total sales. The number of employee-months is calculated from the sum of the product of full-time permanent employee-months (that is, number of full-time permanent employees x 12 months) and the product of full-time seasonal/temporary employee-months (that is, number of full-time seasonal/temporary employee times the average length of employment (in months)).

The use of number of employee-months as the input for labour productivity makes for a more accurate computation of the measure than the mere use of employee numbers [11].

The use of the $\log$ of labour productivity is an appropriate transformation because distributions of productivity are approximately lognormal [12].

The log of labour productivity varies from a minimum of 2.88 to a maximum of 5.78 , with a mean of 4.33 and standard deviation of 0.470 .

The mean of the log of labour productivity is lowest for the garments sub-sector (4.06), and highest for the machinery and equipment sub-sector (4.59). 
The mean of the log of labour productivity also varies with the industry size. It is 4.14 for small-sized firms ( 5 - 19 employees), 4.35 with medium sized firms ( 20 - 99 employees), and 4.57 for large-sized firms (100 employees and more).

\section{B. Independent Variable}

The main independent or explanatory variable, competition, is measured as the number of competitors for a firm's main product line in its main market. The firm responses are coded on a scale of 1 to 4 . 1 representing no competitor, 2 for 1 competitor, 3 for 2-5 competitors, and 4 for more than 5 competitors.

The number of competitors scale varies from a minimum of 1 to a maximum of 4 , with mean of 3.32 and standard deviation of 0.876 . The median and mode have a value of 4 on the scale.

The mean of the number of competitors scale is lowest for the basic metals sub-sector (3.00), and highest for the nonmetallic mineral products sub-sector and electronics sub-sector (3.50).

The mean of this scale also seems to reduce with increasing firm size. It is 3.39 for small firms, 3.35 for medium firms, and 3.17 for large firms.

\section{STATISTICAL ESTIMATION}

In this section, the research estimates the relationship between competition and labour productivity through the linear regression of $\log$ of labour productivity on the number of competitors scale.

Regression analysis is usually used for this kind of estimation [13], [14].

\section{A. Regression on Competition}

The estimation of the regression results are firstly done without any controls or consideration for any other possible independent or explanatory variables apart from that of competition. The results of the coefficients are given in Table I (for model 1).

The specification is as follows:

Log of labor productivity $=$ Constant $+\mathrm{B}_{1}$ (\# of competitors $)+$ error model 1

The analysis has been done across the sub-sectors of the manufacturing industry to find any significant relationships.

The constant or intercept value across all the sub-sectors of the industry are significant at 1 percent except for that of the nonmetallic mineral products where it is at the 10 percent level. It is not significant for the 3 (undefined) sub-sector, and the statistics could not be computed for the basic metals sub-sector.

The number of competitors scale coefficients are only significant at the 10 percent level for the garments, and fabricated metal products sub-sectors. This scale's coefficients are not significant for the other sub-sectors.

The beta standardized coefficient for the number of competitors scale is actually - 0.180 for the garments sub-sector, and -0.163 for the fabricated metal products sub-sector. This should mean that more competition leads to reduced labour productivity (a negative relationship). The relationship is positive for some sub-sectors but these are not significant.

\section{B. Regression on Competition and Size}

The results from the base regression are mostly non-significant, and even when significant are possibly unreliable because many other possible explanatory or predictor variables are not considered or controlled. To improve on this, another linear regression analysis is done with the log of labour productivity on the number of competitors, and also on the size (firm size - whether small, medium, or large). The results of the coefficients are provided in Table II (for model 2).

The specification is as follows:

Log of labour productivity $=$ Constant $+\mathrm{B}_{1}$ (\# of competitors $)+$ $\mathrm{B}_{2}($ Size $)+$ error $_{\text {model } 2}$

As in model 1, the constant or intercept value in model 2 across all the sub-sectors of manufacturing is significant at 1 percent, again, except for that of nonmetallic mineral products which is now non-significant. It is still not significant for the 3 (undefined) sub-sector, and the statistics could not be computed for the basic metals sub-sector.

The number of competitors scale coefficients is only significant at the 10 percent level for the other manufacturing and non metallic mineral products sub-sectors. The coefficients are now significant for the fabricated metal products sub-sector at 5 percent.

The beta standardized coefficient for the number of competitors scale is actually 0.135 for the other manufacturing sub-sector, 0.974 for the non metallic mineral products and -0.181 for the fabricated metal products sub-sector. The values are positive in two instances, and negative in one. Thus, these results are mixed.

The size (firm size) coefficients are only significant at 1 percent for the other manufacturing, food, chemicals, and fabricated metal products sub-sectors. The coefficients are significant at 5 percent for the garments sub-sector.

The beta standardized coefficients for size are 0.340 for the other manufacturing sub-sector, 0.451 for the food sub-sector, 0.308 for the chemicals, 0.410 for the fabricated metal products, and 0.209 for the garments sub-sector. These all show positive association of size with labour productivity.

\section{CONCLUSION}

The results of the estimation of the relationship between competition and labour productivity have not been conclusive. For the majority of the sub-sectors in manufacturing the results were not significant, and for even those that were, the relationship were mixed (some positive, others negative) and fairly large.

When the estimation was done considering or controlling for size as well, the results, essentially, did not change much for the number of competitors scale; although different sub-sectors are now significant for the numbers of competitors. There are more sub-sectors that are significant for the size variable, and the relationship with size being larger than that with the number of competitors scale.

A number of recommendations would most likely improve the results of a future work for this estimation. Firstly, the number of competitors scale can be made more sensitive by 
extending its range at the high end, similarly to the scale in [3]. The scale used here has most of the responses at the maximum, as evidenced with the mean of 3.32, and median and mode being 4 on a scale of 1 to 4 .

It is also very important to have many other relevant explanatory or predictor variables that can be controlled for in the estimation analysis for the relationship between labour productivity and competition, so as to further test this relationship to prove its reliability, validity and robustness with the hope of getting fairly large significant results.

TABLE I: LINEAR REGRESSION WITH NUMBER OF COMPETITORS SCALE

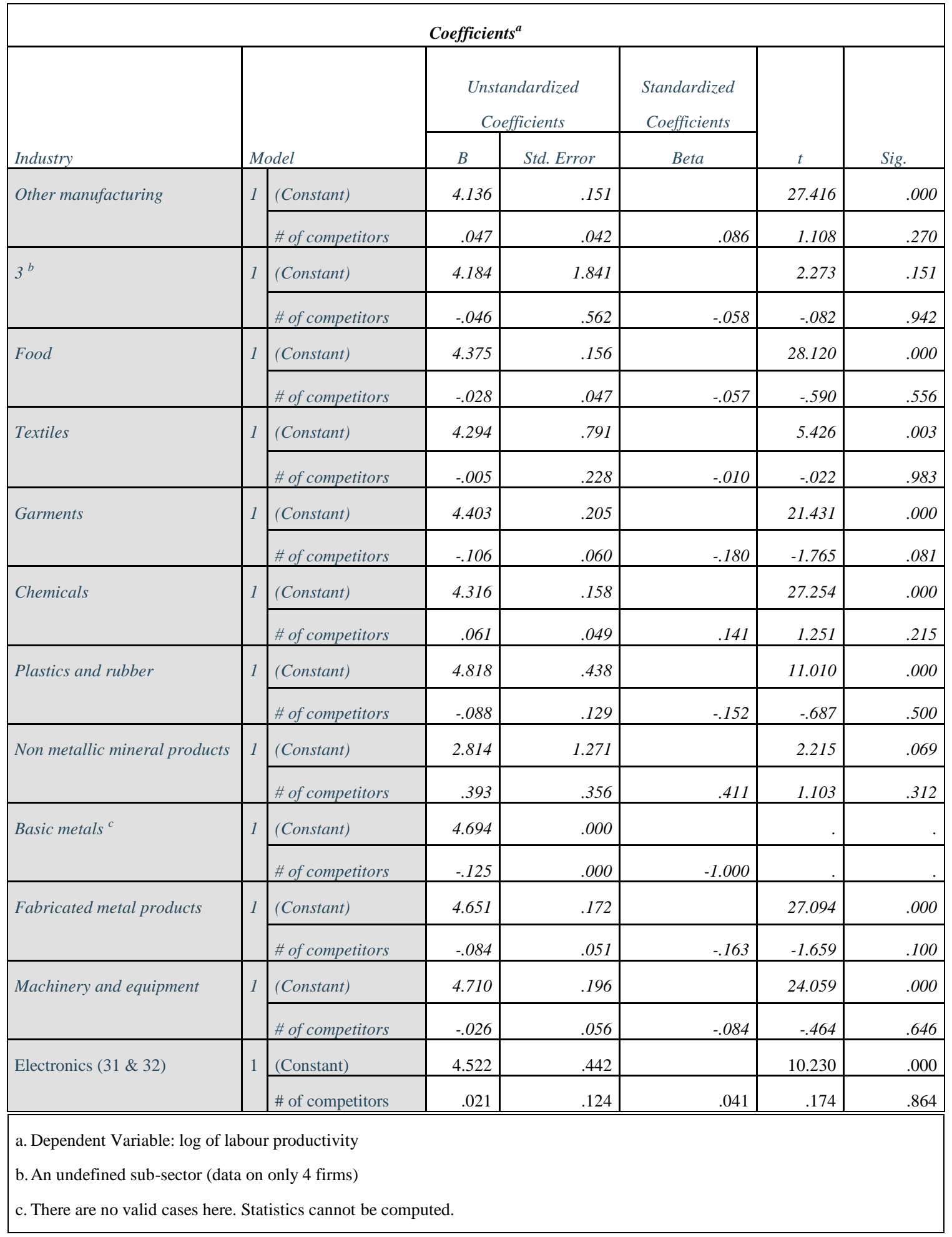


]TABLE II: LINEAR REGRESSION WITH NUMBER OF COMPETITORS SCALE AND SIZE

\begin{tabular}{|c|c|c|c|c|c|c|c|}
\hline \multicolumn{8}{|c|}{ Coefficients $^{\mathrm{a}}$} \\
\hline \multirow[t]{2}{*}{ Industry } & \multicolumn{2}{|r|}{ Model } & \multicolumn{2}{|c|}{ Unstandardized Coefficients } & \multirow{2}{*}{\begin{tabular}{|c|} 
Standardized Coefficients \\
Beta
\end{tabular}} & \multirow[t]{2}{*}{$\mathrm{t}$} & \multirow{2}{*}{ Sig. } \\
\hline & & & $\mathrm{B}$ & Std. Error & & & \\
\hline \multirow[t]{3}{*}{ Other manufacturing } & \multirow[t]{3}{*}{2} & (Constant) & 3.683 & .173 & & 21.256 & .000 \\
\hline & & \# of competitors & .073 & .040 & .135 & 1.824 & .070 \\
\hline & & Size & .202 & .044 & .340 & 4.587 & .000 \\
\hline \multirow[t]{3}{*}{$3^{b}$} & \multirow[t]{3}{*}{2} & (Constant) & 1.840 & 2.630 & & .700 & .611 \\
\hline & & \# of competitors & .380 & .633 & .478 & .600 & .656 \\
\hline & & Size & .639 & .548 & .928 & 1.166 & .451 \\
\hline \multirow[t]{3}{*}{ Food } & \multirow[t]{3}{*}{2} & (Constant) & 3.829 & .174 & & 21.950 & .000 \\
\hline & & \# of competitors & -.026 & .042 & -.053 & -.612 & .542 \\
\hline & & Size & .287 & .055 & .451 & 5.209 & .000 \\
\hline \multirow[t]{3}{*}{ Textiles } & \multirow[t]{3}{*}{2} & (Constant) & 4.934 & .920 & & 5.364 & .006 \\
\hline & & \# of competitors & -.076 & .226 & -.149 & -.337 & .753 \\
\hline & & Size & -.213 & .175 & -.539 & -1.219 & .290 \\
\hline \multirow[t]{3}{*}{ Garments } & \multirow[t]{3}{*}{2} & (Constant) & 4.125 & .242 & & 17.012 & .000 \\
\hline & & \# of competitors & -.094 & .059 & -.160 & -1.593 & .114 \\
\hline & & Size & .140 & .068 & .209 & 2.073 & .041 \\
\hline \multirow[t]{3}{*}{ Chemicals } & \multirow[t]{3}{*}{2} & (Constant) & 3.912 & .208 & & 18.784 & .000 \\
\hline & & \# of competitors & .076 & .047 & .175 & 1.613 & .111 \\
\hline & & Size & .176 & .062 & .308 & 2.830 & .006 \\
\hline \multirow[t]{3}{*}{ Plastics and rubber } & \multirow[t]{3}{*}{2} & (Constant) & 4.483 & .551 & & 8.142 & .000 \\
\hline & & \# of competitors & -.073 & .129 & -.125 & -.560 & .582 \\
\hline & & Size & .148 & .148 & .223 & 1.001 & .330 \\
\hline \multirow{3}{*}{$\begin{array}{l}\text { Non metallic mineral } \\
\text { products }\end{array}$} & \multirow[t]{3}{*}{2} & (Constant) & -1.764 & 2.825 & & -.624 & .560 \\
\hline & & \# of competitors & .931 & .433 & .974 & 2.149 & .084 \\
\hline & & Size & 1.077 & .613 & .797 & 1.758 & .139 \\
\hline \multirow[t]{2}{*}{ Basic metals $^{c}$} & \multirow[t]{2}{*}{2} & (Constant) & 3.694 & .000 & & . & . \\
\hline & & Size & .250 & .000 & 1.000 & . & \\
\hline \multirow[t]{3}{*}{ Fabricated metal products } & 2 & (Constant) & 4.299 & .175 & & 24.595 & .000 \\
\hline & & \# of competitors & -.093 & .046 & -.181 & -2.019 & .046 \\
\hline & & Size & .203 & .045 & .410 & 4.566 & .000 \\
\hline Machinery and equipment & 2 & (Constant) & 4.451 & .290 & & 15.365 & .000 \\
\hline & & \# of competitors & -.005 & .058 & -.017 & -.090 & .929 \\
\hline & & Size & .088 & .073 & .228 & 1.205 & .238 \\
\hline Electronics (31 \& 32) & 2 & (Constant) & 3.982 & .549 & & 7.255 & .000 \\
\hline & & \# of competitors & .047 & .120 & .091 & .395 & .697 \\
\hline & & Size & .191 & .123 & .356 & 1.557 & .138 \\
\hline $\begin{array}{l}\text { Dependent Variable: } \log 0 \\
\text { An undefined sub-sector } \\
\text { There are no valid cases } h\end{array}$ & & $\begin{array}{l}\text { ductivity } \\
4 \text { firms) } \\
\text { s cannot be com }\end{array}$ & & & & & \\
\hline
\end{tabular}

\section{ACKNOWLEDGEMENT}

S.O. Adeyemi thanks the World Bank's Enterprise surveys for making available the dataset used in this research.

\section{REFERENCES}

[1] Stats SA. (2013). Gross Domestic Product (GDP) figures released., Statistics South Africa, http://www.statssa.gov.za/?p=903

[2] G. Djolov, "Competition in the South African manufacturing sector: an empirical probe", South African Journal of Business Management, vol. 46, no. 3, pp 21-29, 2015.

[3] K. Friesenbichler, and M. Peneder, "Innovation, competition and productivity: firm-level evidence for Eastern Europe and Central Asia", Economics of Transition, vol. 24, no. 3, pp 535-580, 2016.

[4] A Murray, "Partial versus Total Factor Productivity measures: an assessment of their strengths and weaknesses", International Productivity Monitor, vol. 31, Fall, pp 113-126, 2016.

[5] H. Van Zyl, "Labour productivity and employee diversity in the South African workplace", Journal of Economic and Financial Sciences, vol. 7, no. 2, pp 451-466, 2014.
[6] H. Horn, H. Lang, and S. Lundgren, "Managerial effort incentives, $\mathrm{X}$-inefficiency and international trade", European Economic Review, vol. 39, pp 117-138, 1995.

[7] K. Schmidt, "Managarial incentives and product market competition", Review of Economic Studies, vol. 64, pp 191-213, 1997.

[8] M. Rogers, "Competition, agency and productivity", International Journal of the Economics of Business, vol. 11, no. 3, pp 349-367, 2004.

[9] S. J. Nickell, "Competition and corporate performance", Journal of Political Economy, vol. 104, no. 4, pp 724-746, 1996.

[10] UN Stats. (2017). Detailed structure and explanatory notes: ISIC Available: Rev.3.1 (International Standard Industrial Classification of All Economic Activities, Rev.3.1), United Nations Statistics Division,

[11] Available: https://unstats.un.org/unsd/cr/registry/regcst.asp?Cl=17.

[12] N. Oulton, "Competition and the dispersion of labour productivity amongst UK companies", Oxford Economic Papers, vol. 50, no. 1, pp 23-38, 1998.

[13] N. Oulton, "Competition and the dispersion of labour productivity amongst UK companies", Discussion Paper No. 103, National Institute of Economic and Social Research, London, 1996.

[14] M. Amin, "Competition and labor productivity in India's retail stores", Journal of Asian Economics, vol. 41, pp 57-68, 2015.

[15] G. Symeonidis, "Competition and the relative productivity of large and small firms", Applied Economics, vol. 43, pp 3253-3264, 2011. 